University of Nebraska - Lincoln

DigitalCommons@University of Nebraska - Lincoln

USDA Wildlife Services - Staff Publications

U.S. Department of Agriculture: Animal and Plant Health Inspection Service

2017

Strength Testing of Raccoons and Invasive Wild Pigs for a Species-Specific Bait Station

\author{
Nathan P. Snow \\ Texas A\&M University-Kingsville, nathan.p.snow@aphis.usda.gov \\ Michael J. Lavelle \\ USDA/APHIS/WS National Wildlife Research Center, michael.j.lavelle@aphis.usda.gov \\ Joseph M. Halseth \\ USDA/APHIS/ Wildlife Services, National Wildlife Research Center \\ Chad R. Blass \\ USDA National Wildlife Research Center \\ Justin A. Foster \\ Texas Parks and Wildlife Department
}

See next page for additional authors

Follow this and additional works at: https://digitalcommons.unl.edu/icwdm_usdanwrc

Part of the Life Sciences Commons

Snow, Nathan P.; Lavelle, Michael J.; Halseth, Joseph M.; Blass, Chad R.; Foster, Justin A.; and VerCauteren, Kurt C., "Strength Testing of Raccoons and Invasive Wild Pigs for a Species-Specific Bait Station" (2017). USDA Wildlife Services - Staff Publications. 1967.

https://digitalcommons.unl.edu/icwdm_usdanwrc/1967

This Article is brought to you for free and open access by the U.S. Department of Agriculture: Animal and Plant Health Inspection Service at DigitalCommons@University of Nebraska - Lincoln. It has been accepted for inclusion in USDA Wildlife Services - Staff Publications by an authorized administrator of DigitalCommons@University of Nebraska - Lincoln. 
Authors

Nathan P. Snow, Michael J. Lavelle, Joseph M. Halseth, Chad R. Blass, Justin A. Foster, and Kurt C. VerCauteren 


\title{
Strength Testing of Raccoons and Invasive Wild Pigs for a Species-Specific Bait Station
}

\author{
NATHAN P. SNOW iD ,1,2 Caesar Kleberg Wildlife Research Institute, Texas AङM University-Kingsville, 700 University Boulevard, MSC 218, \\ Kingsville, TX 78363, USA \\ MICHAEL J. LAVELLE, U.S. Department of Agriculture/Animal and Plant Health Inspection Service/Wildlife Services, National Wildlife Research \\ Center, 4101 LaPorte Avenue, Fort Collins, CO 80521, USA \\ JOSEPH M. HALSETH, U.S. Department of Agriculture/Animal and Plant Health Inspection Service/Wildlife Services, National Wildlife Research \\ Center, 4101 LaPorte Avenue, Fort Collins, CO 80521, USA \\ CHAD R. BLASS, U.S. Department of Agriculture/Animal and Plant Health Inspection Service/Wildlife Services, National Wildlife Research Center, \\ 4101 LaPorte Avenue, Fort Collins, CO 80521, USA \\ JUSTIN A. FOSTER, Kerr Wildlife Management Area, Texas Parks and Wildife Department, 2625 FM 1340, Hunt, TX 78024, USA \\ KURT C. VerCAUTEREN, U.S. Department of Agriculture/Animal and Plant Health Inspection Service/Wildife Services, National Wildlife \\ Research Center, 4101 LaPorte Avenue, Fort Collins, CO 80521, USA
}

\begin{abstract}
With the development of a toxic bait $\left(\mathrm{HOGGONE}^{\mathbb{R}}\right.$ ) for the control of invasive wild pig (IWP; Sus scrofa) populations in the United States, there is a need to develop a bait station to mitigate potential effects on nontarget species. Our objective was to identify characteristics of a bait station that can successfully exclude raccoons (Procyon lotor) - a ubiquitous and dexterous nontarget species-while facilitating bait consumption by IWPs that exhibit group-feeding behaviors. We evaluated abilities of captive raccoons $(n=19)$ and IWPs $(n=41)$ to open the lids of prototype resistance assessment bait stations (RABS) under various levels of resistance $($ range $=1.1-18.1 \mathrm{~kg}$ ) at research facilities in Colorado and Texas, USA, during July-August 2014. We found that similar proportions (0.65) of individual raccoons and IWPs in our tests opened lids with $0-1.4 \mathrm{~kg}$ resistance, which decreased as resistance increased. No raccoons opened lids with $\geq 13.6 \mathrm{~kg}$ of resistance. However, equal proportions (0.45) of IWPs opened lids with $13.6 \mathrm{~kg}$ and $18.1 \mathrm{~kg}$, and a greater proportion (0.73) secondarily accessed RABS after other IWPs opened them. Scrounging behaviors of IWPs (i.e., aggressively taking access to food from less dominate IWPs) increased as the levels of resistance increased, but similar proportions of animals gained access. These results suggest that a threshold-weight-of-resistance of $13.6-18.1 \mathrm{~kg}$ on hinged lids excludes raccoons and allows access by IWPs. Furthermore, bait stations designed to allow multiple IWPs to feed simultaneously may be preferred because of group feeding behaviors. Field evaluations are required to evaluate the exclusion of other nontarget species (e.g., white-tailed deer [Odocoileus virginianus], black bears [Ursus americanus], and coyotes [Canis latrans]), potential scrounging behaviors by nontargets, and bait consumption by IWPs. Published 2017. This article is a U.S. Government work and is in the public domain in the USA.
\end{abstract}

KEY WORDS feeding behavior, feral swine, integrated pest management, nontarget, Procyon lotor, raccoon, Sus scrofa, toxicant.

The abundance and range of invasive wild pigs (IWPs; Sus scrofa) - also termed feral swine, feral pigs, and wild boars (Keiter et al. 2016)—are increasing throughout the world (Woodall 1983, Sáez-Royuela and Telleriia 1986, Hone 1990, Lever 1994). In the United States, IWP populations are damaging agriculture, natural, and cultural resources, and transmitting disease (Mayer and Brisbin 2009, Bevins et al. 2014). Annual U.S. economic losses have been estimated at US $\$ 1.5$ billion from crop damage, depredation of livestock, spread

Received: 26 September 2016; Accepted: 17 December 2016 Published: 25 April 2017

${ }^{1}$ E-mail: nathan.p.snow@aphis.usda.gov

${ }^{2}$ Present Address: U.S. Department of Agriculture/Animal and Plant Health Inspection Service/Wildlife Services, National Wildife Research Center, 4101 LaPorte Avenue, Fort Collins, CO 80521, USA. of disease, and the cost control (Pimentel 2007). Anderson et al. (2016) estimated that IWPs have caused US $\$ 190$ million of losses in crop yields per year throughout 10 high-producing states. In addition to traditional methods used to reduce damage associated with increasing IWP populations, the U.S. Department of Agriculture, Animal Plant Health Inspection Service, Wildlife Services is evaluating the efficacy of using oral baits to reduce population abundance.

Currently a prototype toxic bait, HOGGONE ${ }^{\circledR}$ (Animal Control Technologies Australia P/L, Somerton, Victoria, Australia) containing the active ingredient sodium nitrite is being evaluated for registration in the United States as a toxic bait for IWPs. Despite promise as a highly lethal and humane toxic bait (Cowled et al. 2008, Shapiro et al. 2016) with low secondary risks (Lapidge et al. 2012), strategies for effectively and safely administering HOGGONE ${ }^{\circledR}$ to IWPs 
in natural settings need careful consideration (Cowled et al. 2008, Ballesteros et al. 2009, Bengsen et al. 2011, Kittawornrat and Zimmerman 2011). In particular, nontarget species should not be put at risk (Bengsen et al. 2010, 2011; Long et al. 2010; Lapidge et al. 2012; Campbell et al. 2013). The HOGGONE ${ }^{\mathbb{B}}$ prototype consists of a peanut paste and crushed-grains bait matrix that is attractive to many species (Snow et al. 2016); therefore, a bait station must be designed that excludes nontarget animals within the range of IWPs (e.g., raccoons [Procyon lotor], white-tailed deer [Odocoileus virginianus], black bears [Ursus americanus], coyotes [Canis latrans], among other species).

An ideal IWP-specific bait station will effectively deliver toxic bait to large proportions of the target population. For instance, Hone (2007) estimated that 0.52 proportion of IWP population must be removed annually to stop population growth. Secondly, a bait station must exclude access by all nontarget animals to reduce unintentional hazards to these species. Lastly, a bait station should facilitate various social structures and feeding behaviors of IWPs, such as solitary (i.e., adult male IPW) or group (i.e., multiple adult female IWPs with offspring) feeding behaviors (Mayer 2009). Earlier designs of bait stations, such as the HogHopper $^{\text {TM }}$ (Lapidge et al. 2012) or the Boar-OperatedSystem (BOS ${ }^{\mathrm{TM}}$; Massei et al. 2010), addressed these challenges, but reported reductions in consumption by IWPs attributed to the bait stations (Long et al. 2010, Massei et al. 2010, Campbell et al. 2013), or nontarget access to the baits or spilled baits (Brooks et al. 1990, Long et al. 2010, Massei et al. 2010). In addition, HOGGONE ${ }^{\mathbb{R}}$ is a paste that is deployed in plastic trays. Previous bait stations were designed for pelleted, cylindrical, or bolus baits and do not easily accommodate trays of paste. A bait station with a hinged lid is desirable for access to the trays. In addition, this design of bait station could deliver any form of baits containing other pharmaceuticals such as vaccines or contraceptives (e.g., Ballesteros et al. 2009).

A unique and exploitable behavior of IWPs is rooting, the overturning and lifting of soil and vegetation to find food. The earlier designs of bait stations attempted to exploit this behavior by requiring IWPs to lift on handles or rims just above ground level (e.g., Ernst et al. 2005, Massei et al. 2010, Campbell et al. 2012). Another potentially exploitable characteristic of IWPs is their physical strength. The most commonly reported nontarget species in the southern United States with the highest densities of IWPs included raccoons, white-tailed deer, and various species of birds (Campbell and Long 2007, Snow et al. 2016). These species are smaller than IWPs and less capable of moving heavy objects. Adult IWPs in the United States average $70-100 \mathrm{~kg}$ depending on sex, and are capable of overturning soil and large objects (e.g., rocks and logs) to find food (Mayer and Brisbin 2009). Black bears, another potential nontarget species, have a high degree of physical strength, but are less geographically distributed and exist in lower densities than the nontarget species mentioned above (e.g., McLean and Pelton 1994, Pelton and Van Manen 1994, Boersen et al. 2003). Therefore, the risk to black bears may be mitigated by careful site selection for areas with few bears and seasonal baiting while bears are in dens (e.g., Johnson and Pelton 1980, Oli et al. 1997).

We focused on a primary nontarget species of concern, the raccoon. Raccoons are ubiquitous across North America and overlap with IWPs in space-use and food resource needs (Lotze and Anderson 1979, Mayer and Brisbin 2009). Raccoons represent an appropriately challenging nontarget species for developing bait stations because they exhibit high levels of problem-solving and cognitive abilities (Davis 1984). Subsequently, raccoons were the primary nontarget species that gained access to previous designs of IWP-specific bait stations (Long et al. 2010; Campbell et al. 2011, 2013).

Another important consideration for IWPs is their feeding behavior. Invasive wild pigs reportedly exhibit 1 of 2 feeding strategies- "producer" and "scrounger" (Held et al. 2010). Producers are often smaller and subordinate animals that forage on the periphery of social groups. Scroungers represent larger and dominant animals that exploit producers after the producers have located and accessed desirable food items. These group-feeding behaviors have been observed at other bait stations (Long et al. 2010; Campbell et al. 2011, 2013; Ferretti et al. 2014). Massei et al. (2010) reported both feeding behaviors as being highly important for allowing access to all IWPs using the BOS $^{\mathrm{TM}}$ bait station. Not all IWPs are equally capable or willing to independently access bait; therefore, ensuring that both producers and scroungers have opportunities to consume bait is critical.

Our primary objective was to identify a threshold-weightof-resistance that facilitated access by IWPs, but excluded raccoons to prototype bait stations. To our knowledge, no comparisons between the physical strength of raccoons and IWPs have been conducted, particularly related to lifting lids to access bait stations. Our goal was to determine a maximum weight that would restrict raccoons. Our secondary objective was to compare the proportions of IWPs that accessed prototype bait stations using producer or scrounger behaviors. The results of this study will be used to inform the development of a new, IWP-specific bait station for the large-scale delivery of HOGGONE ${ }^{\mathbb{R}}$ or other pharmaceuticals to control populations of invasive IWPs with minimal risks to nontarget species.

\section{STUDY AREA}

We conducted all testing during July-August, 2014. We tested raccoons inside open-air research buildings at the U.S. Department of Agriculture, Animal Plant and Health Inspection Service, Wildlife Services, National Wildlife Research Center (NWRC), Fort Collins, Colorado, USA. We tested IWPs in an outdoor research facility at the Texas Parks and Wildlife, Kerr Wildlife Management Area, Hunt, Texas, USA.

\section{METHODS}

\section{Resistance Assessment Bait Station}

We developed a resistance assessment bait station (RABS) to assess the abilities of raccoons and IWPs to lift a lid under 
various weights of resistance. The RABS were $55 \times 29 \times$ 31- $\mathrm{cm}$ boxes constructed of 4.4- $\mathrm{cm}$-thick, untreated pine lumber treated with food-grade sealant (Fig. 1). The top of the RABS was constructed as a horizontally mounted, hinged lid that provided access to a reservoir below. The lids automatically closed using gravitational force. The lid included a $5-\mathrm{cm}$ overhang on the front edge of the box to provide a lifting point for opening. We achieved known weights of resistance by attaching a 15.24-cm tool bar magnet (Master Magnets, Inc., Castle Rock, CO, USA) on the inner frame of the box. We attached various lengths of flat strip steel (i.e., hot rolled mild steel; $2.54 \times 0.32 \mathrm{~cm}$ ) ranging from $4.45 \mathrm{~cm}$ to $7.62 \mathrm{~cm}$ long to the underside of the lid where they made contact with the magnet and provided desired weights of resistance. We determined exact weight of resistance with a precision spring scale (Macro-Item 80020; Pesola Company, Baar, Switzerland) mounted below a fence post puller (PP-300; Hi-Lift Post-Popper, Bloomfield, IN, USA), which provided a controlled and consistent vertical pull.

We filled the lower portion of the RABS reservoirs with $20 \mathrm{~kg}$ of concrete to reduce tipping and movement by animals. The remaining space of the reservoir was used for holding food items. For training, we installed a temporary block $(5.08 \mathrm{~cm})$ to prop the lid and allow raccoons and IWPs to acclimate to accessing food resources inside the RABS. During testing, we removed the block.

\section{Raccoon Strength Testing}

During July 2014, we tested $n=19$ adult, captive raccoons that were individually housed in adjacent cages $(3 \times 3 \times 2.5$ $\mathrm{m})$. We tested 10 female and 9 male raccoons with average mass of $6.5 \mathrm{~kg}(\mathrm{SD}=0.4)$ and $8.0 \mathrm{~kg}(\mathrm{SD}=1.6)$, respectively. We fed raccoons approximately $180 \mathrm{~g}$ of MAZURI ${ }^{\circledR}$
Omnivore-Zoo Feed “A” (Land O' Lakes, Inc., St. Paul, $\mathrm{MN}$, USA) as a maintenance diet daily. To increase motivation to access the RABS, we reduced daily rations to $80 \%$ of the normal maintenance diet (Angermeier et al. 1987, Day et al. 1995, Seaman et al. 2008) and added 2 dried pitted plums during the trials. We placed these reduced rations inside of the RABS (i.e., $1 \mathrm{RABS} /$ individual raccoon cage) during the trials. We provided water ad libitum to all raccoons during the trial.

We conducted raccoon trials over 8 consecutive days. We filled the RABS with rations at routine morning feeding hours each day. We removed any uneaten food and replaced it the following morning. During Day 1, we secured the lids of the RABS completely open to allow raccoons to acclimate to accessing food in the RABS. During Day 2, we left the lids propped approximately $4 \mathrm{~cm}$ using the temporary block. During Day 3, we removed the block and closed the lids without installing magnets (i.e., $1.1 \mathrm{~kg}$ of resistance from weight of lid). During Days 4, 5, 6, 7, and 8, we closed the lids with magnets engaged at $2.7,5.4,8.2,10.9$, and $13.6 \mathrm{~kg}$ of resistance, respectively. We measured resistances on all RABS before and after each trial-day to ensure consistency of targeted weights.

We monitored the RABS and raccoons using motionactivated cameras (Reconyx RC60 Covert IR; Reconyx, Inc., Holmen, WI, USA) and determined access by reviewing imagery data and weighing the amount of food remaining each day. If a raccoon failed to gain access during a day, we tested the raccoon again at the same level of resistance for a second day. If the raccoon failed to gain access the second day, we concluded the animal was not capable of gaining access at the current level of resistance or greater, and ceased the trial for that animal. If the raccoon gained access the

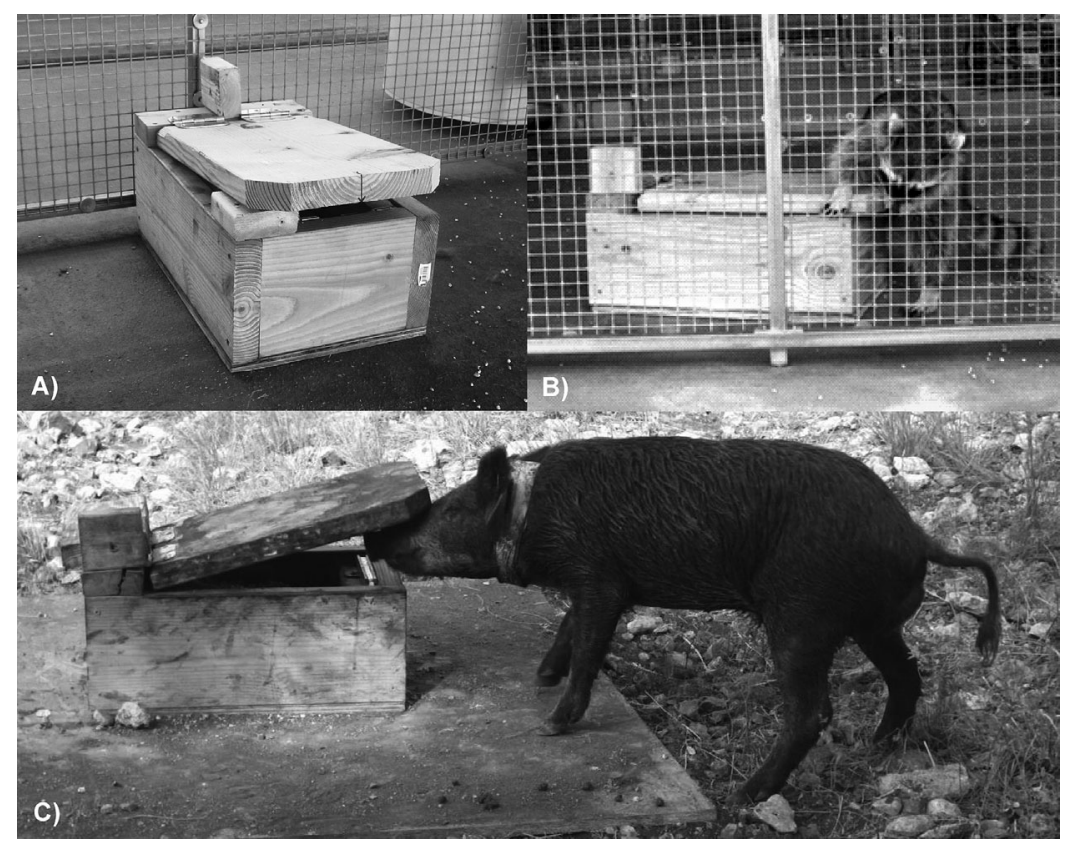

Figure 1. (A) Resistance assessment bait station (RABS) propped open with a temporary block. (B) A captive raccoon attempting to open the lid of a RABS in July 2014, National Wildlife Research Center, Fort Collins, CO, USA. (C) An invasive wild pig opening the lid of a RABS in August 2014, Kerr Wildlife Management Area, Hunt TX, USA. 
second day, the trial proceeded to the next level of resistance the following day. After the trials ceased, we removed the RABS and returned raccoons to their regular maintenance feeding schedule.

\section{Invasive Wild Pig Strength Testing}

During August 2014, we tested $n=41$ subadult ( $>2$ months and $<1 \mathrm{yr}$ ) and adult ( $>1 \mathrm{yr}$ ) captive IWPs that were group housed in a 2-ha outdoor pen. The groups consisted of 21 female and 20 male pigs with average mass of $27.8 \mathrm{~kg}$ $(\mathrm{SD}=5.6)$ and $27.2 \mathrm{~kg}(\mathrm{SD}=6.8)$, respectively. We marked all with unique combinations of ear tags (All American ${ }^{\circledR}$ 2-piece tags; Y-Tex Corp., Cody, WY, USA), livestock marking paint (Swine Shot ${ }^{\circledR}$ Spray Paint; LA-CO Industries, Inc., Elk Grove Village, IL, USA), and uniquely patterned collars of tape (Duck Tape ${ }^{\mathbb{R}}$; Avon, OH, USA) to identify individual animals. We fed IWPs a maintenance diet (18\% Sow Ration Pellet; AC Nutrition, Winters, TX, USA) offered at approximately $1.8 \%$ of group body mass daily. We increased motivation to access the RABS by reducing the daily rations to $70 \%$ of normal maintenance diet (Angermeier et al. 1987, Day et al. 1995, Seaman et al. 2008). We divided the reduced rations equally among 9 RABS, and placed the RABS $>50 \mathrm{~m}$ apart in the pen. We provided water ad libitum to all IWPs from one automatic trough during the trial.

We completed the IWP group trials during 5 consecutive days. We removed from the RABS any uneaten food and replaced it the following day. We mounted the RABS on $1.22-\mathrm{m}^{2}$ sheets of plywood staked to the ground to reduce movement and tipping. During Days 1, 2, and 3, we positioned lids of the RABS as open, propped slightly open with the temporary block, and closed without magnets installed (i.e., $1.1 \mathrm{~kg}$ of resistance from weight of lid), respectively. During Days 4 and 5, we closed the lids with magnets engaged at 13.6 and $18.1 \mathrm{~kg}$, respectively.

We monitored the RABS and IWPs using motion-activated cameras (Reconyx PC900) focused on the RABS and immediate surrounding area. We recorded the individuals that gained access into the RABS. We also differentiated between producer and scrounger feeding events by individual (Held et al. 2000). We considered producer events as those animals that gained access to the RABS by opening the lids. We considered scrounger events as those animals that exploited others by stealing access (i.e., accessing the RABS by pushing out a producer) or sharing access to a previously opened RABS. Study protocols were approved by the NWRC Institutional Animal Care and Use Committee (protocol: QA-2263).

\section{Data Analysis}

We examined all photo images using the Colorado Parks and Wildlife Photo Database for image processing (v3.0; Ivan and Newkirk 2016). For raccoons, we examined the proportion of animals that opened the boxes under the various levels of resistance. We examined similar proportions for IWPs, as well as secondary accesses into the boxes. We reported proportional results as 1) proportion of raccoons that opened boxes; 2) proportion of IWPs that opened boxes; and 3) proportion of IWPs that gained access to the boxes (i.e., opened boxes+secondary accesses).

For IWPs, we examined linear mixed-effects models using package lme4 (Bates et al. 2015) in Program R (v3.1.1; R Development Core Team, https://cran.r-project.org/manuals. $\mathrm{html}$ ) to examine how changes in resistance influenced access to the RABS. We examined 3 models including different response variables: 1 ) counts of all accesses to the RABS (i.e., producers+scroungers); 2) counts of IWPs that opened the lids and accessed the RABS (i.e., producers); and 3) counts of IWPs that stole access to the RABS from other animals (i.e., scroungers). For each model, we treated the 4 categorical states of the RABS (i.e., propped open with temporary block, closed without resistance from magnets, closed with magnets engaged at $13.6 \mathrm{~kg}$, and closed with magnets engaged at $18.1 \mathrm{~kg}$ ) as the levels of treatment. We used the lids propped open with a temporary block as the reference treatment, to which we compared all other treatments. We considered the position of each of the 9 RABS within the pen as random blocking effect (i.e., North 1, North 2, North 3, Middle 1, Middle 2, Middle 3, South 1, South 2, South 3) to account for any locational effects. We used $95 \%$ confidence intervals to test for lack of overlap on zero on the regression coefficients $(\beta)$ to provide evidence that the level of resistance influenced the number of IWPs that accessed, opened, or stole access to the RABS, respectively.

\section{RESULTS}

We found that 13 of 19 (0.68) tested raccoons opened the lids once they were completely closed with resistance limited to the weight of the lid (Fig. 2). The same 13 raccoons opened the lids with $2.7 \mathrm{~kg}$ and $5.4 \mathrm{~kg}$ of resistance. Eight of 19 (0.42) raccoons tested opened lids with $8.2 \mathrm{~kg}$ of resistance, but only 3 of 19 (0.16) opened with $10.9 \mathrm{~kg}$ of resistance. None of the raccoons opened lids with $13.6 \mathrm{~kg}$ of resistance.

We identified that 27 of 41 IWPs (0.66) opened propped lids with no resistance beyond the weight of the lid, and 25 of 41 (0.61) opened lids that were completely closed with no resistance except the weight of the lid (Fig. 2). Completely closing the lids ceased access by 5 animals that accessed when the lid was propped. Twenty of $41(0.49)$ animals opened lids with $13.6 \mathrm{~kg}$ of resistance, and 19 of 41 (0.46) animals opened lids with $18.1 \mathrm{~kg}$ of resistance. Fewer IWPs per RABS opened the lids when the magnets were engaged at $13.6 \mathrm{~kg}(\beta=-4.33,95 \%$ $\mathrm{CI}=-7.54$ to -1.13 ; Fig. 3 ), but this difference subsided the following day when the resistance was increased to $18.1 \mathrm{~kg}$ $(\beta=-0.56,95 \% \mathrm{CI}=-3.76-2.65)$. Three of 41 (0.07) animals were never documented as gaining access to the RABS.

We found no differences in the average number of IWPs that accessed the boxes (producers+scroungers) among the different levels of resistance (Fig. 3). However, behaviors of IWPs shifted with increasing resistance. More IWPs scrounged when the greatest amount of resistance was tested $(\beta=3.33,95 \% \mathrm{CI}=1.45-5.22)$. Many IWPs exhibited both producer and scrounger behaviors. Of 28 IWPs that opened the lids at some point in the study (i.e., producers), 18 were also documented stealing access (i.e., scroungers). Thirteen of those 18 began scrounging only 


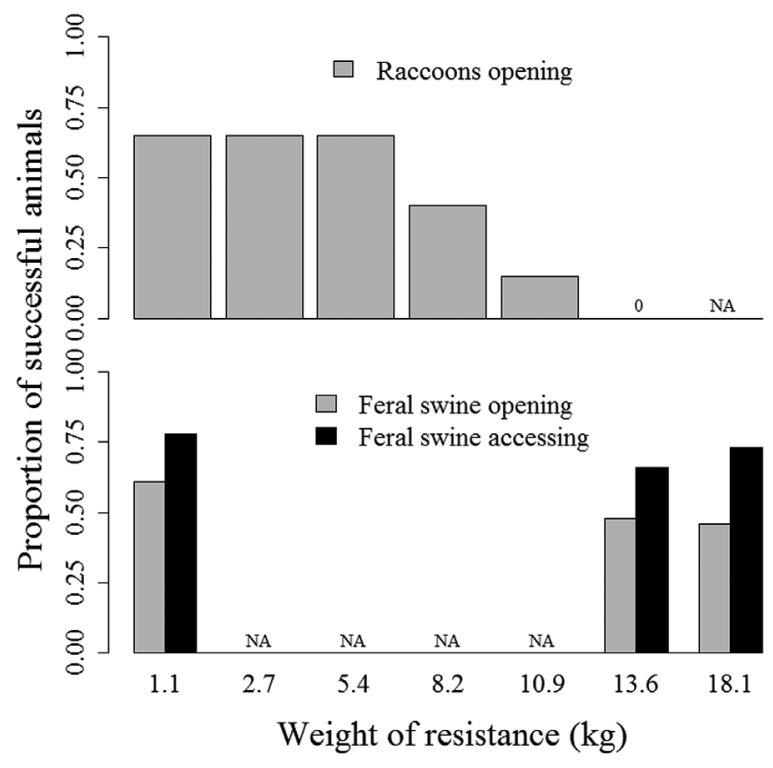

Figure 2. Proportion of $n=19$ individual raccoons and a group of $n=41$ invasive wild pigs that opened the lids of a resistance assessment bait station (RABS) under various weight of resistance during July-August 2014 at the National Wildlife Research Center, Fort Collins, CO, USA (raccoons) and Kerr Wildlife Management Area, Hunt TX, USA (invasive wild pigs). Also shown is the total proportion of invasive wild pigs that gained access to the RABS by opening or stealing access. Weights of resistance showing not applicable (NA) proportions were not tested for that particular species.

after the lids were completely closed. The opposite change from scrounger to producer was less evident. Only 3 of 16 scroungers switched to being producers. Overall, nearly $50 \%$ of IWPs opened the RABS and nearly $75 \%$ accessed the RABS by producing or scrounging.

\section{DISCUSSION}

We identified that approximately $13.6 \mathrm{~kg}$ of resistance provided an exploitable divergence between the abilities of raccoons and IWPs to open lids for the development of an IWP-specific bait station. No raccoons gained access to the RABS at this level of resistance, whereas nearly $75 \%$ of IWPs accessed the RABS. Furthermore, a similar proportion of IWPs opened the RABS under a greater level of resistance $(18.1 \mathrm{~kg})$. Previous research demonstrated that IWPs are capable of opening bait stations with resistance of $\geq 15 \mathrm{~kg}$ (Long et al. 2010, Massei et al. 2010). Combined, these findings suggest that the range of exploitable resistance between raccoons and IWPs is quite large (i.e., $\leq 4.5 \mathrm{~kg}$ ).

Complete exclusion of raccoons from RABS was achieved with a resistance of $13.6 \mathrm{~kg}$, providing a minimum level of resistance to prevent unintentional delivery of HOG$\mathrm{GONE}^{\mathbb{R}}$ to raccoons. This level of resistance was also successful in eliminating access by raccoons in previous field trials (Long et al. 2010). Raccoons and IWPs have been observed in the field at bait sites feeding together; thus, it is possible that raccoons could secondarily access bait stations as scroungers (e.g., Snow et al. 2016). Given the physical and cognitive abilities of raccoons, we expect that bait stations using lids with $\geq 13.6 \mathrm{~kg}$ of resistance should be sufficient for excluding direct access by most nontarget species that overlap the current range of IWPs except for black bears in North America.

The social feeding behaviors of IWPs were found to be an important consideration for development of a bait station. Approximately $60 \%$ of IWPs acted as producers and opened lids when there was no resistance except the weight of the lid (i.e., $1.1 \mathrm{~kg}$ ). This demonstrates that many IWPs are willing and capable of opening lids and accessing food. Given the low level of resistance, the impediment for nonopeners must lie in behavioral or cognitive limitations. Fortunately, the scrounging behaviors of IWPs help overcome these limitations because nonopeners can exploit the producing behaviors of their associates (e.g., Held et al. 2002, Massei et al. 2010). In our study, shifts between producer and
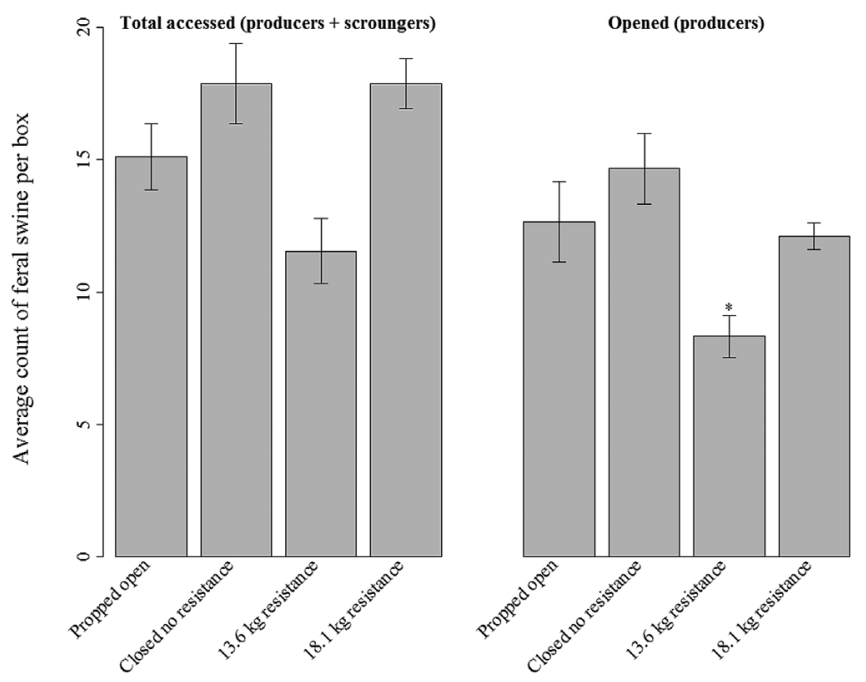

Accessed without opening (scroungers)

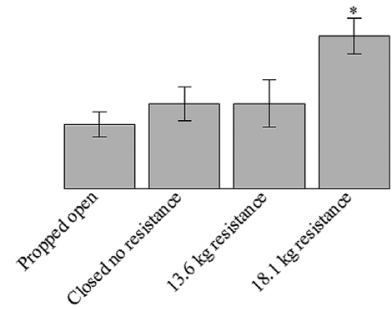

Figure 3. The average number and standard errors from a group of $n=41$ invasive wild pigs that accessed, opened, or stole access to 9 resistance assessment bait station (RABS) in a 2-ha outdoor pen under various weights of resistance in August 2014, Kerr Wildlife Management Area, Hunt TX, USA. Asterisks designate a lack of overlap on zero for $95 \%$ confidence intervals of parameter estimates for that level of resistance. 
scrounging behavior allowed most IWPs to access the RABS. Scrounging behaviors increased under increasing levels of resistance. These results reflect previous findings of swine adjusting their social foraging tactics as competition increases (Held et al. 2000, 2002). Considering both behaviors, designs of IWP-specific bait stations should enable multiple IWPs to feed simultaneously, following a single opening event by a single producer. This design will also accommodate feeding by the various social structures of IWPs, ranging from solitary adult male IWPs to sounders of adult female IPWs with offspring (e.g., Mayer 2009).

Interestingly, we found that the progression from the closed lid to $13.6 \mathrm{~kg}$ of resistance resulted in a temporary drop in IWPs accessing RABS. We expect this occurred as a temporary response to the novel challenge of increased resistance, similar to other findings with IWPs (Long et al. 2010). It is evident that the acclimation and learning process for IWPs can be slow when considering novel challenges for accessing food (Kornum and Knudsen 2011, Campbell et al. 2012). Generally, a learning period following introduction of a bait station is required (Campbell et al. 2011, 2012). As additional changes occur, there is likely to be an aversive response or a temporary setback in access until new learned behaviors are developed to meet requirements for accessing feed (Ernst et al. 2005). In our study, the temporary aversion subsided quickly and was nonexistent when the next level of resistance $(18.1 \mathrm{~kg})$ was tested, suggesting $\geq 1$ day may be needed to acclimate IWPs to accessing bait stations after resistance is added to the lids. From this result, we also expect that proportions of IWP accessing the RABS would have increased with a longer duration of testing.

The overall finding that nearly $75 \%$ of IWPs accessed the RABS is promising for the eventual population control of IWPs using a toxic bait. Assuming that similar proportions of IWPs consume lethal doses of a toxic bait from bait stations in practice, the removal rate would be enough to effectively stop population growth and reduce populations of IWPs (Hone 2007). Examination of juvenile IWPs ( $<2$ months) gaining access to bait stations is an important line of future research for successful population control. We hypothesize that juveniles will secondarily access a bait station if opened by a subadult or adult IWP. Finally, 7\% of IWPs in this test did not access the RABS, indicating that bait avoidance behavior may reduce the complete effectiveness of a toxic bait for IWPs. An integrated pest-management strategy will be vital for successful population control of IWPs.

\section{MANAGEMENT IMPLICATIONS}

Differences in physical abilities between raccoons and IWPs demonstrate an exploitable characteristic of IWP-specific bait stations to ensure safe delivery of HOGGONE ${ }^{\mathbb{R}}$ or other pharmaceuticals to IWPs with full exclusion of a ubiquitous nontarget species. Hinged lids using a threshold weight of resistance (i.e., $13.6-18.1 \mathrm{~kg}$ ) will secure the lids of bait stations to exclude raccoons, and likely other nontarget species. Magnets provide a simple means to provide the resistance without necessitating a heavy lid that may further reduce feeding by IWPs. Invasive wild pigs that do not open the lids access the bait station though scrounging, but aggressive behaviors associated with scrounging can reduce efficient delivery to all animals in groups of IWPs. As such, bait stations should be designed to facilitate feeding by multiple IWPs simultaneously to accommodate producers and scroungers. Field evaluations are required to evaluate the exclusion of other nontarget species (e.g., white-tailed deer, black bears, coyotes, and others), potential scrounging behaviors by nontargets, and bait consumption by IWPs including juveniles.

\section{ACKNOWLEDGMENTS}

We thank the National Wildlife Research Center (NWRC) Rabies project for providing raccoons, and the U.S. Department of Agriculture Texas Wildlife Services for providing invasive wild pigs for testing. E. Newkirk provided technical assistance with developing the photo image database. J. Kinsey assisted with marking IWPs. We thank anonymous reviewers and the Associate Editor for insightful reviews and contribution to this manuscript. We thank the NWRC and Texas Parks and Wildlife Department Kerr Wildlife Management Area for providing facilities. Funding and support of this research were provided by the NWRC, the Association of Fish \& Wildlife Agencies, and the Animal and Plant Health Inspection Service National Feral Swine Damage Management Program. Mention of commercial products or companies does not represent an endorsement by the U.S. government.

\section{LITERATURE CITED}

Anderson, A., C. Slootmaker, E. Harper, J. Holderieath, and S. A. Shwiff. 2016. Economic estimates of feral swine damage and control in 11 US states. Crop Protection 89:89-94.

Angermeier, W., J. Mclean, D. Minvielle, and C. Grue. 1987. Foodrewarded operant learning in the opossum. Bulletin of the Psychonomic Society 25:23-26.

Ballesteros, C., C. Gortázar, M. Canales, J. Vicente, A. Lasagna, J. A. Gamarra, R. Carrasco-García, and J. De la Fuente. 2009. Evaluation of baits for oral vaccination of European wild boar piglets. Research in Veterinary Science 86:388-393.

Bates, D., M. Mächler, B. Bolker, and S. Walker. 2015. Fitting linear mixed-effects models using lme4. arXiv preprint arXiv:1406.5823. Journal of Statistical Software 67:1-48.

Bengsen, A., L. Leung, S. Lapidge, and I. Gordon. 2011. Testing targetspecific bait delivery for controlling feral pigs in a tropical rainforest. Ecological Management \& Restoration 12:226-229.

Bengsen, A. J., L. K.-P. Leung, S. J. Lapidge, and I. J. Gordon. 2010. Artificial illumination reduces bait-take by small rainforest mammals. Applied Animal Behaviour Science 127:66-72.

Bevins, S. N., K. Pedersen, M. W. Lutman, T. Gidlewski, and T. J. Deliberto. 2014. Consequences associated with the recent range expansion of nonnative feral swine. BioScience 64:291-299.

Boersen, M. R., J. D. Clark, and T. L. King. 2003. Estimating black bear population density and genetic diversity at Tensas River, Louisiana using microsatellite DNA markers. Wildlife Society Bulletin 31:197-207.

Brooks, J. E., E. Ahmad, I. Husaain, S. Munir, M. H. Khan, and M. M. Asif. 1990. Field evaluation of candidate toxicants, baits, and bait delivery systems for control of wild boar. U.S. Department of Agriculture Unpublished Technical Report No. 23, Animal Plant and Health Inspection Service, Wildlife Research Center, Denver, Colorado, USA.

Campbell, T. A., M. J. Bodenchuk, J. D. Eisemann, S. J. Lapidge, L. Staples, and P. Morrow. 2012. Preliminary assessment of the HogHopper ${ }^{\mathrm{TM}}$ for excluding non-target wildlife. Pages 333-336 in R. M. Timm, editor. Proceedings of the 25th vertebrate pest conference. University of California, Davis, USA. 
Campbell, T. A., J. A. Foster, M. J. Bodenchuk, J. D. Eisemann, L. Staples, and S. J. Lapidge. 2013. Effectiveness and target-specificity of a novel design of food dispenser to deliver a toxin to feral swine in the United States. International Journal of Pest Management 59:197-204.

Campbell, T. A., and D. B. Long. 2007. Species-specific visitation and removal of baits for delivery of pharmaceuticals to feral swine. Journal of Wildlife Diseases 43:485-491.

Campbell, T. A., D. B. Long, and G. Massei. 2011. Efficacy of the BoarOperated-System to deliver baits to feral swine. Preventive Veterinary Medicine 98:243-249.

Cowled, B. D., P. Elsworth, and S. J. Lapidge. 2008. Additional toxins for feral pig (Sus scrofa) control: identifying and testing Achilles' heels. Wildlife Research 35:651-662.

Davis, H. 1984. Discrimination of the number three by a raccoon (Procyon lotor). Animal Learning \& Behavior 12:409-413.

Day, J., I. Kyriazakis, and A. Lawrence. 1995. The effect of food deprivation on the expression of foraging and exploratory behaviour in the growing pig. Applied Animal Behaviour Science 42:193-206.

Ernst, K., B. Puppe, P. C. Schön, and G. Manteuffel. 2005. A complex automatic feeding system for pigs aimed to induce successful behavioural coping by cognitive adaptation. Applied Animal Behaviour Science 91:205-218.

Ferretti, F., A. Sforzi, J. Coats, and G. Massei. 2014. The BOS ${ }^{\text {TM }}$ as a species-specific method to deliver baits to wild boar in a Mediterranean area. European Journal of Wildlife Research 60:555-558.

Held, S., M. Mendl, C. Devereux, and R. W. Byrne. 2000. Social tactics of pigs in a competitive foraging task: the 'informed forager' paradigm. Animal Behaviour 59:569-576.

Held, S., M. Mendl, C. Devereux, and R. W. Byrne. 2002. Foraging pigs alter their behaviour in response to exploitation. Animal Behaviour 64:157-165.

Held, S. D., R. W. Byrne, S. Jones, E. Murphy, M. Friel, and M. T. Mendl. 2010. Domestic pigs, Sus scrofa, adjust their foraging behaviour to whom they are foraging with. Animal Behaviour 79:857-862.

Hone, J. 1990. How many feral pigs in Australia. Wildlife Research 17:571-572.

Hone, J. 2007. Wildlife damage control. CSIRO, Collingwood, Victoria, Australia.

Ivan, J. S., and E. S. Newkirk. 2016. CPW Photo Warehouse: a custom database to facilitate archiving, identifying, summarizing and managing photo data collected from camera traps. Methods in Ecology and Evolution 7:499-504.

Johnson, K. G., and M. R. Pelton. 1980. Environmental relationships and the denning period of black bears in Tennessee. Journal of Mammalogy 61:653-660.

Keiter, D. A., J. J. Mayer, and J. C. Beasley. 2016. What is in a "common" name? A call for consistent terminology for nonnative Sus scrofa. Wildlife Society Bulletin 40:384-387.

Kittawornrat, A., and J. J. Zimmerman. 2011. Toward a better understanding of pig behavior and pig welfare. Animal Health Research Reviews 12:25-32.

Kornum, B. R., and G. M. Knudsen. 2011. Cognitive testing of pigs (Sus scrofa) in translational biobehavioral research. Neuroscience \& Biobehavioral Reviews 35:437-451.
Lapidge, S., J. Wishart, L. Staples, K. Fagerstone, T. Campbell, and J. Eisemann. 2012. Development of a feral swine toxic bait $\left(\mathrm{Hog}-\mathrm{Gone}^{\mathbb{R}}\right.$ ) and bait hopper (Hog-Hopper ${ }^{\mathrm{TM}}$ ) in Australia and the USA. Pages 19-24 in S. N. Frey, editor. Proceedings of the 14 th wildlife damage management conference. University of Lincoln, Nebraska, USA.

Lever, C. 1994. Naturalized animals: the ecology of successfully introduced species. T and A. D. Poyser Ltd., London, England.

Long, D. B., T. A. Campbell, and G. Massei. 2010. Evaluation of feral swine-specific feeder systems. Rangelands 32:8-13.

Lotze, J.-H., and S. Anderson. 1979. Procyon lotor. Mammalian Species 119:1-8.

Massei, G., J. Coats, R. Quy, K. Storer, and D. P. Cowan. 2010. The BoarOperated-System: a novel method to deliver baits to wild pigs. Journal of Wildlife Management 74:333-336.

Mayer, J. J. 2009. Wild pig behavior. Pages 77-104 in J. Mayer, and I. L. Brisbin Jr., editors. Wild pigs biology, damage, control, techniques, and management. Savannah River National Laboratory, Aiken, South Carolina, USA.

Mayer, J. J., and I. L. Brisbin, editors. 2009. Wild pigs: biology, damage, control techniques and management. Savannah River National Laboratory, SRNL-RP-2009-00869, Aiken, South Carolina, USA.

McLean, P. K., and M. R. Pelton. 1994. Estimates of population density and growth of black bears in the Smoky Mountains. Bears: Their Biology and Management 9:253-261.

Oli, M. K., H. A. Jacobson, and B. D. Leopold. 1997. Denning ecology of black bears in the White River National Wildlife refuge, Arkansas. Journal of Wildlife Management 61:700-706.

Pelton, M., and F. Van Manen. 1994. Distribution of black bears in North America. Eastern Workshop for Black Bear Research and Management 12:133-138.

Pimentel, D. 2007. Environmental and economic costs of vertebrate species invasions into the United States. Pages 2-8 in G. W. Witmer, W. C. Pitt, and K. A. Fagerstone, editors. Managing vertebrate invasive species: proceedings of an international symposium. U.S. Department of Agriculture, Animal and Plant Health Inspection Service, Wildlife Services, National Wildlife Research Center, Fort Collins, Colorado, USA.

Sáez-Royuela, C., and J. Telleriia. 1986. The increased population of the wild boar (Sus scrofa L.) in Europe. Mammal Review 16:97-101.

Seaman, S. C., N. K. Waran, G. Mason, and R. B. D'Eath. 2008. Animal economics: assessing the motivation of female laboratory rabbits to reach a platform, social contact and food. Animal Behaviour 75:31-42.

Shapiro, L., C. Eason, C. Bunt, S. Hix, P. Aylett, and D. MacMorran. 2016. Efficacy of encapsulated sodium nitrite as a new tool for feral pig management. Journal of Pest Science 89:489-495.

Snow, N. P., J. M. Halseth, M. J. Lavelle, T. E. Hanson, C. R. Blass, J. A. Foster, S. T. Humphrys, L. D. Staples, D. G. Hewitt, and K. C. VerCauteren. 2016. Bait preference of free-ranging feral swine for delivery of a novel toxicant. PLoS ONE 11:e0146712.

Woodall, P. F. 1983. Distribution and population dynamics of dingoes (Canis familiaris) and feral pigs (Sus scrofa) in Queensland, 1945-1976. Journal of Applied Ecology 20:85-95.

Associate Editor: Messmer. 